\title{
Characterization of Bacterial Communities in Bioaerosols over Northern Chinese Marginal Seas and the Northwestern Pacific Ocean in Spring
}

\author{
MANMAN MA, Yu ZHEN, AND TIEZHU Mi \\ Key Laboratory of Marine Environment and Ecology, Ministry of Education, and Laboratory for Marine Ecology \\ and Environmental Science, Qingdao National Laboratory for Marine Science and Technology, and College \\ of Environmental Science and Engineering, Ocean University of China, Qingdao, Shandong, China
}

(Manuscript received 21 May 2018, in final form 23 January 2019)

\begin{abstract}
Studies of the community structures of bacteria in marine aerosols of different particle sizes have not been reported. Aerosol samples were collected using a six-stage bioaerosol sampler over the Bohai Sea, the Yellow Sea, and northwestern Pacific Ocean in the spring of 2014. The diversity and composition of these samples were investigated by Illumina high-throughput sequencing, and 130 genera were detected in all of the samples; the most abundant bacterial genus was Bacteroides, followed by Prevotella and Megamonas. The Chao1 and Shannon diversity indices ranged from 193 to 1044 and from 5.44 to 8.33, respectively. The bacterial community structure in coarse particles (diameter larger than $2.1 \mu \mathrm{m}$ ) was more complex and diverse than that in fine particles (diameter less than $2.1 \mu \mathrm{m}$ ) in marine bioaerosols from over the Yellow Sea and northwestern Pacific Ocean, while the opposite trend was observed for samples collected over the Bohai Sea. Although we were sampling over marine regions, the sources of the bioaerosols were mostly continental. Temperature and wind speed significantly influenced the bacterial communities in marine aerosols of different particle sizes. There may be a bacterial background in the atmosphere in the form of several dominant taxa, and the bacterial communities are likely mixed constantly during transmission.
\end{abstract}

\section{Introduction}

Bioaerosols are airborne particles or large molecules that consist of viruses, bacteria, fungi, pollen, and plant or animal debris as well as fragments and products of these organisms (Ariya and Amyot 2004; Grinshpun and Clark 2005). Bioaerosols can potentially serve as cloud condensation nuclei (CCN; Bauer et al. 2003; Franc and Demott 1998) and ice nucleating particles (INP; Christner 2010; Garcia et al. 2012; Vali et al. 2015) and influence cloud cover and precipitation (Deleon-Rodriguez et al. 2013) and even the global climate (Van Leuken et al. 2016). Bioaerosols also have apparent effects on air quality and human health (Ho and Duncan 2005; Kalogerakis et al. 2005; Ma et al. 2017). Therefore, studies of the composition and structures of microbial communities in aerosols are of great importance for a comprehensive understanding of the effects of aerosols on the climate, environment, and human health.

Many studies have focused on the concentrations and community structures (the composition of a microbial

Corresponding author: Yu Zhen, zhenyu@ouc.edu.cn community and the abundance of its members) of airborne microorganisms, especially terrestrial airborne microorganisms. The concentrations of bioaerosols exhibit significant seasonal variations, and the seasonal variations in different regions are distinctly different (Qi et al. 2014; Dong et al. 2016). Qi et al. (2015) have proposed a fluorescein diacetate (FDA) hydrolysis method for measuring microbial activity in bioaerosols, representing the intensity of microbial metabolic activity, which can be used to indicate the physiological state of microbes. Microbial activity in bioaerosols can be affected by the season, the region, and meteorological factors (Zhong et al. 2016). In the coastal region of Qingdao, microbial activity in bioaerosols is significantly influenced by atmospheric temperature and wind speed, and the seasonal level of microbial activity in bioaerosols from greatest to least is summer, autumn, winter, and spring (Zhong et al. 2016). The structures of bacterial communities change with the presence of haze or dust. The presence of haze can affect bacterial community structures in aerosols. For example, bacterial composition and diversity in the atmosphere vary significantly during dust events, which may carry particles from grasslands (phyllosphere), dry lakes, and 
sandy surfaces, and some bacterial populations, such as Firmicutes and Bacteroidetes, are maintained in the atmosphere for longer time periods (Maki et al. 2017). In addition, pathogenic bacteria detected on hazy days may pose health risks (Ma et al. 2017; Xu et al. 2017).

Studies on microbial communities in aerosols of different particle sizes have also been performed, mainly focusing on terrestrial aerosol microorganisms. Bacterial communities vary significantly among fractions of different sizes during severe occurrences of haze in Jinan, China (Xu et al. 2017). Polymenakou et al. (2008) found that, based on phylogenetic analyses, atmospheric microbial community structure depends on particle size and that the presence of aerosolized bacteria in small size particles may have had significant implications on human health via intercontinental transportation of pathogens during an intense African dust event in the eastern Mediterranean. Particle size distribution can act as a factor affecting the capacity of biological particles to act as cloud condensation nodules (CNs) or INP, thereby influencing their atmospheric transport and processing (Diehl et al. 2001; Morris et al. 2004; Fröhlich-Nowoisky et al. 2016). Particle size can affect the distance, speed, and height of aerosol transmission, which is of great significance to the spread and distribution of microorganisms. The study also found that size matters more than chemistry for the cloud nucleating ability of aerosol particles (Dusek et al. 2006). Therefore, the study of microbial composition of different particle sizes has important environmental and ecological significance.

Oceans cover approximately $70 \%$ of the world's surface and are the main source and sink of atmospheric microbes. Marine aerosol plays a role as a main vector for the transport of bacteria across the air-sea interface and the long-distance dispersal of bacterial species (Aller et al. 2005). Marine bioaerosol microorganisms have been studied recently. High-throughput sequencing technology has shown that bacterial communities in marine aerosols are more complex and diverse than previously thought, and the communities over remote marine regions are shaped by the sources of air mass (Xia et al. 2015). Uncultured Betaproteobacteria, Sphingomonas sp., and uncultured Acidovorax sp. were the dominant bacteria in aerosol samples collected above the Yellow Sea (Wu 2014). Over the East Sea (Korean Peninsula), the abundance of marine aerosol bacteria was found to range from $0.7 \times 10^{3}$ to $1.2 \times 10^{3}$ cells per cubic meter, and the bacterial community was dominated by Gammaproteobacteria and Bacteroidetes (Cho and Hwang 2011). Seifried et al. (2015) found that the most abundant phyla were Proteobacteria, Bacteroidetes, Actinobacteria, and Firmicutes in marine bioaerosols sampled during a cruise from the North Sea to the Baltic Sea via Skagerrak and Kattegat. Bacterial concentrations in the marine air were found to be positively correlated with wind speed near the sea surface of the northwestern Pacific Ocean (Hu et al. 2017).

Studies on the community structures of microbes in marine aerosols of different particle sizes are very limited. To preliminarily understand the characteristics of marine aerosol bacterial community structures of different particle sizes and their possible influencing factors, we studied bacterial community structures in marine aerosols with different particle sizes from over the Bohai Sea, the Yellow Sea, and northwestern Pacific Ocean via Illumina high-throughput sequencing, which provide information for future studies.

\section{Materials and methods}

\section{a. Sample collection}

Three sets of bioaerosol samples were collected from the Bohai Sea (BHS) and the Yellow Sea (YS1, YS2) during a ship cruise, while two sets of bioaerosol samples were collected from the Yellow Sea (YS3) and the northwestern Pacific Ocean (NWP) during another ship cruise. All of the samples were collected in the spring of 2014 (Fig. 1). A sterilized sampler and filter membranes were used for sampling. Size-segregated aerosol samples were collected on $0.22-\mu \mathrm{m}$ polycarbonate membrane filters (Shenghechengxin Membrane Science and Technology Development Center of Beijing, China) for $1 \mathrm{~h}$ with a sampling flow rate of approximately $28.3 \mathrm{~L} \mathrm{~min}^{-1}$ using a six-stage microorganism FA-1 cascade impactor (Applied Technical Institute of Liaoyang, China). After the sampler was sterilized with $75 \%$ alcohol and $15 \mathrm{~min}$ of ultraviolet radiation on a clean bench, the sampler was wrapped in a fresh-keeping bag and placed on the sampling rack for sampling, ensuring that the sampler was sterile before each sampling. The sampler was placed approximately $15 \mathrm{~m}$ above sea level. To avoid contaminants from the ship's exhaust, the sampler was fixed in front of the uppermost deck and worked only when the ship was sailing. The aerosol particles were fractionated into the following six stages based on size: 0.65 $1.1,1.1-2.1,2.1-3.3,3.3-4.7,4.7-7.0$, and $>7.0 \mu \mathrm{m}$, which are referred to as classes 1-6, respectively, in this paper. After sampling, the filters were stored at $-20^{\circ} \mathrm{C}$ for future analysis.

The meteorological parameters (temperature, relative humidity, wind speed, and wind direction) (Table 1) measured by the meteorological observatory on the research vessel were recorded during sampling. 


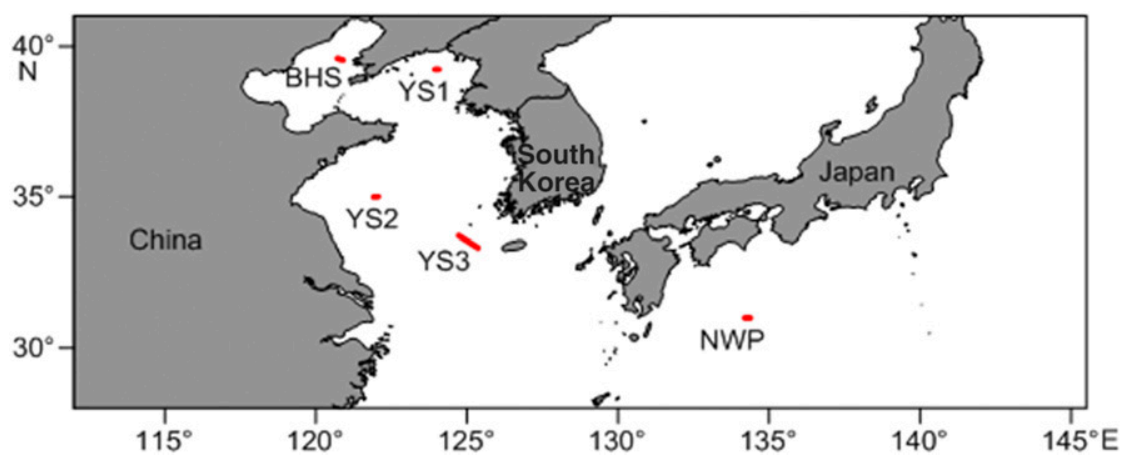

FIG. 1. Sampling transects in the spring of 2014 in the Bohai Sea, the Yellow Sea, and northwestern Pacific Ocean. Each transect represents a total sampling time of $1 \mathrm{~h}$.

\section{b. DNA extraction and Illumina high-throughput sequencing}

Genomic DNA was extracted from aerosol samples of each particle size using the QIAamp DNA Mini Kit (Qiagen, Germany) according to the manufacturer's protocol. The extracted DNA was stored at $-80^{\circ} \mathrm{C}$ prior to further analysis.

The community characteristics of marine bioaerosol bacteria were studied via Illumina sequencing of the $16 \mathrm{~S}$ rRNA gene. Fragments of the 16S rRNA gene [ 466 base pairs (bp), V3-V4 region] were amplified using the primer pair 341F (5'-CCTACGGGRSGCAGCAG) and 806R (5'-GGACTACCAGGGTATCTAAT) (Roggenbuck et al. 2014). Specific primers with barcodes were synthesized before polymerase chain reaction (PCR) amplification. PCR amplification was performed using the KAPA HiFi HotStart ReadyMix (Kapa Biosystems, United States) in a $30-\mu \mathrm{L}$ reaction containing $15 \mu \mathrm{L}$ of $2 \times$ KAPA HiFi Hotstart ReadyMix, $0.2 \mu \mathrm{M}$ forward and reverse primers and approximately $10 \mathrm{ng}$ of template DNA. Touchdown PCR was performed under the following conditions: initial denaturation at $95^{\circ} \mathrm{C}$ for $3 \mathrm{~min}$; 12 cycles (in which the temperature was decreased by $0.5^{\circ} \mathrm{C}$ every other cycle during annealing and time was increased by $1 \mathrm{~s}$ in every other cycle during extension) of $98^{\circ} \mathrm{C}$ for $15 \mathrm{~s}$, annealing at $72^{\circ}-66.5^{\circ} \mathrm{C}$ for $10 \mathrm{~s}$, extending at $72^{\circ} \mathrm{C}$ for $10-21 \mathrm{~s}, 94^{\circ} \mathrm{C}$ for $20 \mathrm{~s}$, annealing from $65^{\circ}$ to $59.5^{\circ} \mathrm{C}$ for $10 \mathrm{~s}$, and extending at $72^{\circ} \mathrm{C}$ for $10-21 \mathrm{~s} ; 11$ cycles of $94^{\circ} \mathrm{C}$ for $20 \mathrm{~s}, 58^{\circ} \mathrm{C}$ for $30 \mathrm{~s}$ and $72^{\circ} \mathrm{C}$ for $30 \mathrm{~s}$; and a final extension step at $72^{\circ} \mathrm{C}$ for $2.5 \mathrm{~min}$. The PCR products were analyzed via $2 \%$ agarose gel electrophoresis and purified using the AxyPrep DNA Gel Extraction Kit (Axygen, United States). The libraries were quantified using a Thermo NanoDrop 2000 ultraviolet microspectrophotometer and $2 \%$ agarose gel electrophoresis. Then, the libraries were quantified using a Qubit 2.0 fluorometer (Invitrogen, Life Technologies), mixed at equal concentration and subsequently sequenced on the Illumina HiSeq 2500 (PE250) platform following the manufacturer's instructions. The $16 \mathrm{~S}$ rDNA sequencing was performed by the Realbio Genomics Institute (Shanghai, China). Raw sequences were submitted to the Sequence Read Archive (SRA) of the National Center for Biotechnology Information (NCBI) database under the accession number SRP128887.

\section{c. Processing and analysis of sequencing data}

A total of 30 samples with different particle sizes were collected from the five sites. Four samples (YS1, 3.3$4.7 \mu \mathrm{m}$ and $>7.0 \mu \mathrm{m}$; YS2, $>7.0 \mu \mathrm{m}$; and NWP, $3.3-$ $4.7 \mu \mathrm{m}$ ) could not be sequenced because of the low concentrations of the extracted DNA, which possibly reflected the low abundances of microorganisms in these particles. During the sequencing process, both ends of a DNA sequence can be sequenced. First, one end is measured, a read is obtained, paired-end turnaround occurs, and the other end is sequenced to obtain another read. The two reads obtained are paired-end $(\mathrm{PE})$ reads.

TABLE 1. Meteorological parameters at the beginning of sampling.

\begin{tabular}{llcccc}
\hline \hline & Sampling date & Temperature $\left({ }^{\circ} \mathrm{C}\right)$ & Relative humidity $(\%)$ & Wind speed $\left(\mathrm{m} \mathrm{s}^{-1}\right)$ & Wind direction $\left({ }^{\circ}\right)$ \\
\hline BHS & 13 May 2014 & 14.8 & 85.20 & 10.5 & 222 \\
YS1 & 17 May 2014 & 13.3 & 91.90 & 5.3 & 339 \\
YS2 & 30 Apr 2014 & 13.8 & 93.20 & 11 & 235 \\
YS3 & 18 Mar 2014 & 11.9 & 78.70 & 6.4 & 12 \\
NWP & 19 Apr 2014 & 19.8 & 81.30 & & 65 \\
\hline
\end{tabular}


PE reads were assigned to the samples based on their unique barcodes, truncated by removing the barcode and primer sequences and then merged using paired-end assembler for Illumina sequences (PANDAseq, version 2.9; Masella et al. 2012). The merged reads were subsequently subjected to quality-based filtering with the analysis platform of the Realbio Genomics Institute. Briefly, average read quality scores below 20 and reads containing more than three ambiguous bases were discarded. The read length range was 220-500 nucleotides (nt). Singletons were filtered, while operational taxonomic units (OTUs) were clustered with a 97\% similarity cutoff using UPARSE (version 7.0.1001, http:// drive5.com/uparse/) (Edgar 2013); chimeric sequences were identified and removed. All samples were normalized at the same sequencing depth. The OTUs obtained after normalization were used as a basis for calculating metrics associated with alpha diversity and beta diversity. The most abundant sequence from each OTU was selected as the representative sequence for sequence alignment. Sequences were classified based on the Ribosomal Database Project (RDP) database (http://rdp.cme.msu.edu) (Cole and Tiedje 2014) at a confidence threshold of $80 \%$. Statistical analyses of the OTU alpha diversity of each aerosol sample based on the Chao1 index (species richness), Good's coverage estimator (coverage), and Shannon diversity index (species diversity) were performed using Quantitative Insights Into Microbial Ecology (QIIME) 1.9.0 software (Caporaso et al. 2010). Richness simply denotes the number of species, as an unweighted measure of species number, while species diversity is a function of the number of species present and the evenness with which the individuals are distributed among these species (Delang and Li 2013; Sanjit and Bhatt 2005).

\section{d. Airmass backward trajectories}

Backward trajectories of all the sampled air masses were created using the Hybrid Single-Particle Lagrangian Integrated Trajectory model (HYSPLIT; Draxler and Rolph 2013). Five-day backward trajectories (Singh et al. 2001; Zhu et al. 2015; Seifried et al. 2015) were calculated for air parcels from the $1000-\mathrm{m}$ air layers based on the GDAS1 meteorological dataset and the model vertical velocity vertical motion method.

\section{Results}

\section{a. Bacterial community diversity in marine bioaerosols}

The Good's coverage estimates for the bioaerosol samples from all of the sites were higher than $99.9 \%$
TABLE 2. Atmospheric bacterial community diversity in marine aerosols.

\begin{tabular}{lccc}
\hline & Chao1 & Shannon & Good's coverage $(\%)$ \\
\hline BHS & 1209.2 & 7.010 & 100 \\
YS1 & 1465.4 & 7.755 & 100 \\
YS2 & 1872.1 & 6.855 & 100 \\
YS3 & 2425.0 & 8.049 & 99.9 \\
NWP & 1400.8 & 7.347 & 100 \\
\hline
\end{tabular}

(Table 2), suggesting that the sequencing effort covered a majority of the bacterial communities. The rarefaction curves for the samples gradually became smooth (Figs. 2a,b), indicating that the sequencing capacity was large enough to capture the complete diversity of these communities. The Chao1 index indicated that the richness of the aerosol bacterial communities was highest at the YS3 site and lowest at the BHS site. Bacterial community richness showed the trend, from greatest to least: Yellow Sea, northwestern Pacific Ocean, and Bohai Sea; and the bacterial richness in the south Yellow Sea aerosols was higher than that in the north Yellow Sea aerosols. The Shannon index indicated that the diversity of aerosol bacterial communities was the highest at the YS3 site and lowest at the YS2 site. Aerosol bacterial community diversity showed the trend, from greatest to least: Yellow Sea, northwestern Pacific Ocean, and the Bohai Sea.

\section{b. Bacterial community composition in marine bioaerosols}

A total of 724152 reads were clustered into 4448 unique OTUs with a $97 \%$ similarity cutoff. The bioaerosol samples from the five sites had 259 shared OTUs (Fig. 3), accounting for $5.82 \%$ of the total OTUs.

All of the OTUs were classified into 32 known bacterial phyla with confidence score thresholds of $80 \%$ (Fig. 4a). Nineteen shared phyla were present in aerosol samples from the five sites, and sequences of these phyla from the five sites represented $89.50 \%$ of all bacterial sequences. The most abundant bacterial phylum (represented highest proportion of all bacterial sequences) detected was Bacteroidetes (26.99\%), followed by Firmicutes $(26.72 \%)$ and Proteobacteria (21.82\%). The relative abundances (percentage of sequences) of these three phyla were more than $80 \%$ at the BHS, YS1, and NWP sites, while they were less than $65 \%$ at the YS2 and YS3 sites. Among all of the detected phyla, SR1 was detected only at the BHS site, and Elusimicrobia and Lentisphaerae were detected only at the NWP site.

At the genus level (Fig. 4b), 71.03\% of all bacterial sequences were assigned to 533 bacterial genera. 


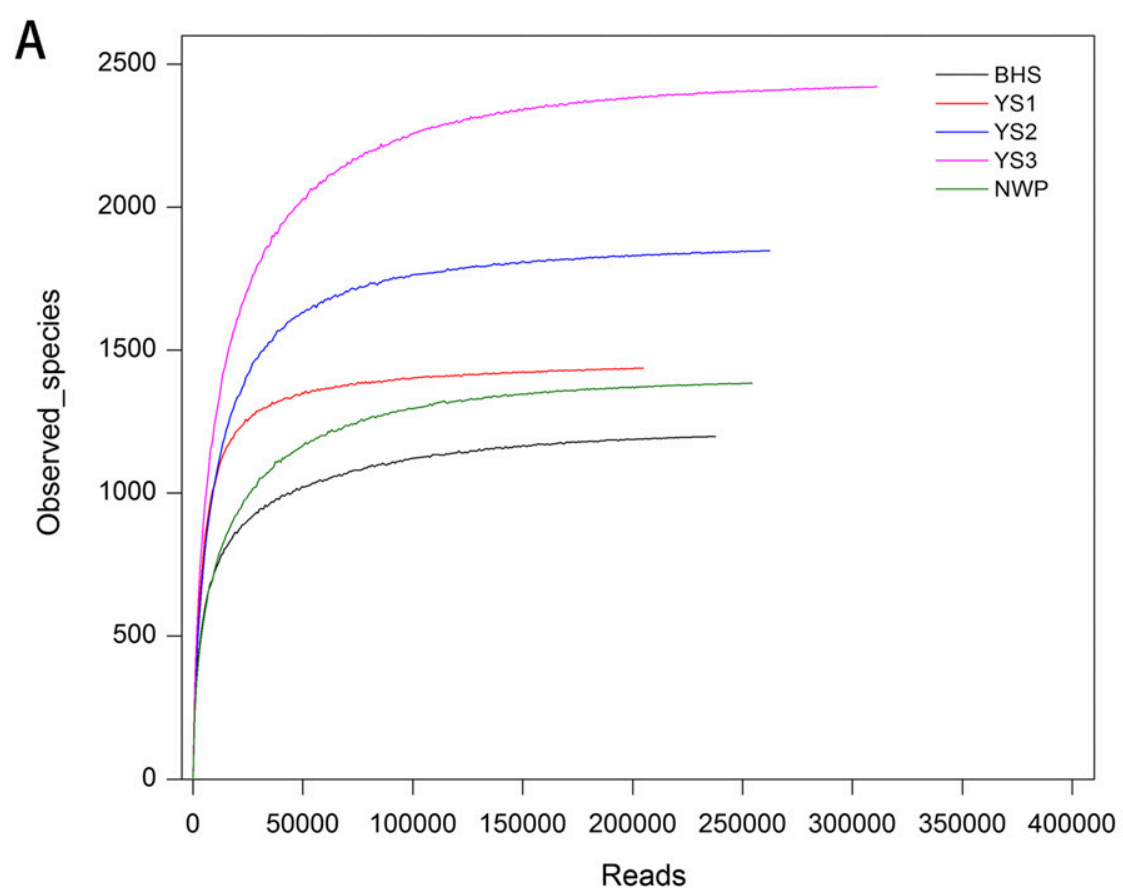

B

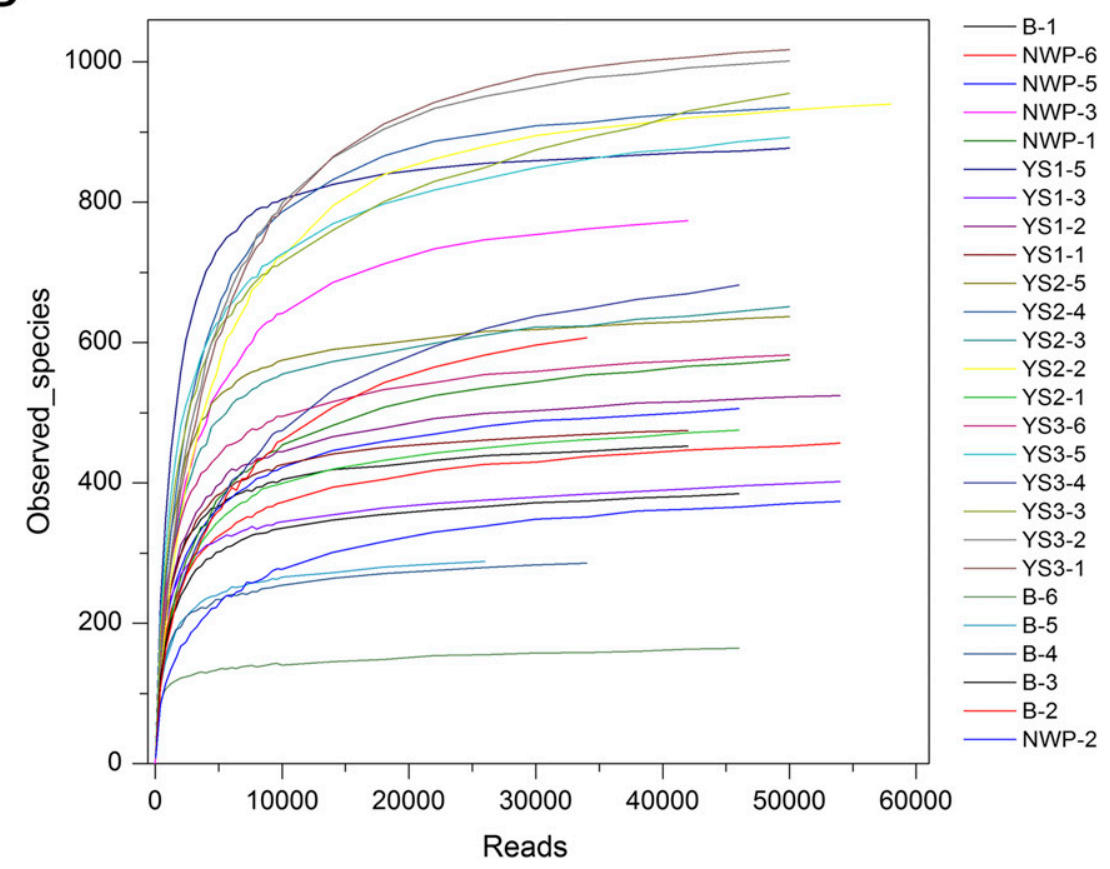

FIG. 2. Rarefaction curves of aerosol samples (a) from different sites and (b) of different particle sizes.

We detected 130 of the genera (63.60\% of all bacterial sequences) at all of the sites. The most abundant bacterial genus detected was Bacteroides $(9.56 \%)$, followed by Prevotella (5.42\%) and Megamonas (3.22\%). The dominant genera in the bacterial communities of bioaerosols from different sites were different. The dominant bacteria were Bacteroides, Prevotella, and Paracoccus at the BHS site; Bacteroides, Prevotella, and Sphingomonas at the YS1 site; Pseudomonas and Bacteroides at the YS2 and YS3 sites; and Bacteroides, Alistipes, Prevotella, and Barnesiella at the NWP site. 


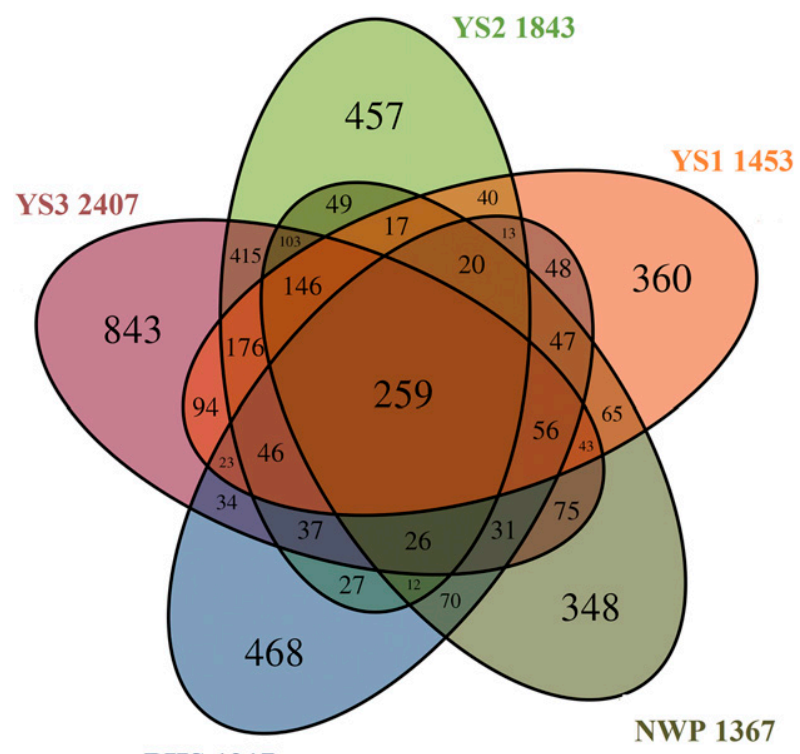

BHS 1217

FIG. 3. Venn diagram of OTUs in marine bioaerosols from different sites.

\section{c. Bacterial community structures of marine bioaerosols with different particle sizes}

The number of OTUs for 26 successfully sequenced samples of different particle sizes ranged from 154 to 975. The Chao1 indices ranged from 193 to 1044, and the Shannon diversity indices ranged from 5.44 to 8.33 (Fig. 5a). Through double factors-no repeated variance analysis - we found that there was a significant difference among the richness of different sites $(p<0.05)$, there was no significant difference in the richness among different particle sizes $(p>0.05)$, and there were significant differences in the diversity among different sites $(p<0.05)$ and different particle sizes $(p<0.05)$.

Particles larger than $2.1 \mu \mathrm{m}$ in diameter were referred to as coarse particles (c) in the sampler stages, and those less than $2.1 \mu \mathrm{m}$ in diameter were referred to as fine particles (f). The richness and diversity of the bacterial community in the coarse particles $(>2.1 \mu \mathrm{m})$ from the Bohai Sea site were lower than those in the fine particles $(<2.1 \mu \mathrm{m})$ (Fig. 5b), while the richness and diversity of the bacterial communities in the coarse particles at the other four sites were higher than those in the fine particles.

The dominant bacteria in the bacterial communities of bioaerosols from different sites were different, and the bacterial compositions of the coarse and fine particles from the same site also varied (Fig. 6). For example, Paracoccus was clearly a dominant genus in fine particles from the Bohai Sea site. The bacterial community structures in fine particles from the YS3 site were similar to the bacterial community structures in aerosols of most particle sizes from the YS2 site, and among these particles, Pseudomonas was the dominant genus. The dominant genera of the coarse particle sizes at the same site were generally more similar, but the dominant genera of fine particle sizes were quite different except for those of the YS3 site. Shared species at different classification levels for each particle size sampled are shown in Table 3 . The genera shared by the 26 samples accounted for $20.30 \%$ of all of the assigned genera. Shared bacteria accounted for $84.60 \%$ of all bacterial sequences at the phylum level and $38.11 \%$ at the genus level.

To compare bacterial community compositions among samples of different particle sizes, jackknifed beta diversity and hierarchical clustering analyses based on unweighted (Fig. 7a) and weighted (Fig. 7b) UniFrac distance metrics were performed. In the analysis based on unweighted UniFrac distance, the difference of the bacterial taxa contained in the aerosols at the same site was relatively small. In the analysis based on weighted UniFrac distance, all of the samples were divided into three branches. The bacterial community composition at the YS2 site was similar to that in fine particles at the YS3 site. In the remaining two branches, both samples from the same site and samples with the same particle sizes did not exhibit obvious similarities. In particular, samples with coarse particle sizes and fine particle sizes from the Bohai Sea site were clustered into two separate branches.

\section{d. Influence of meteorological factors on marine bioaerosol bacterial community structures}

Analysis of the community data showed that canonical correspondence analysis (CCA) was more suitable for analyzing the relationship between the community composition of airborne bacteria and environmental factors. CCA (Fig. 8) and permutation tests were performed to examine the relationships between meteorological factors and bacterial community structures in marine aerosols.

Based on the relationship between environmental factors and bacterial community composition in samples of different particle sizes (Fig. 8a), the environmental factors on the first- and second-ordinal axes accounted for $68.54 \%$ of the cumulative variance between species and environmental factors. Temperature $(p=0.001)$ and wind speed $(p=0.019)$ had significant effects on the bacterial community composition of aerosols of different particle sizes from different sites.

Based on the relationship between environmental factors and bacterial community structures in fine (Fig. 8b) and coarse (Fig. 8c) particles, the first two axes accounted for $69.78 \%$ and $64.04 \%$, respectively, of all the variance, as explained by CCA. Four meteorological factors 

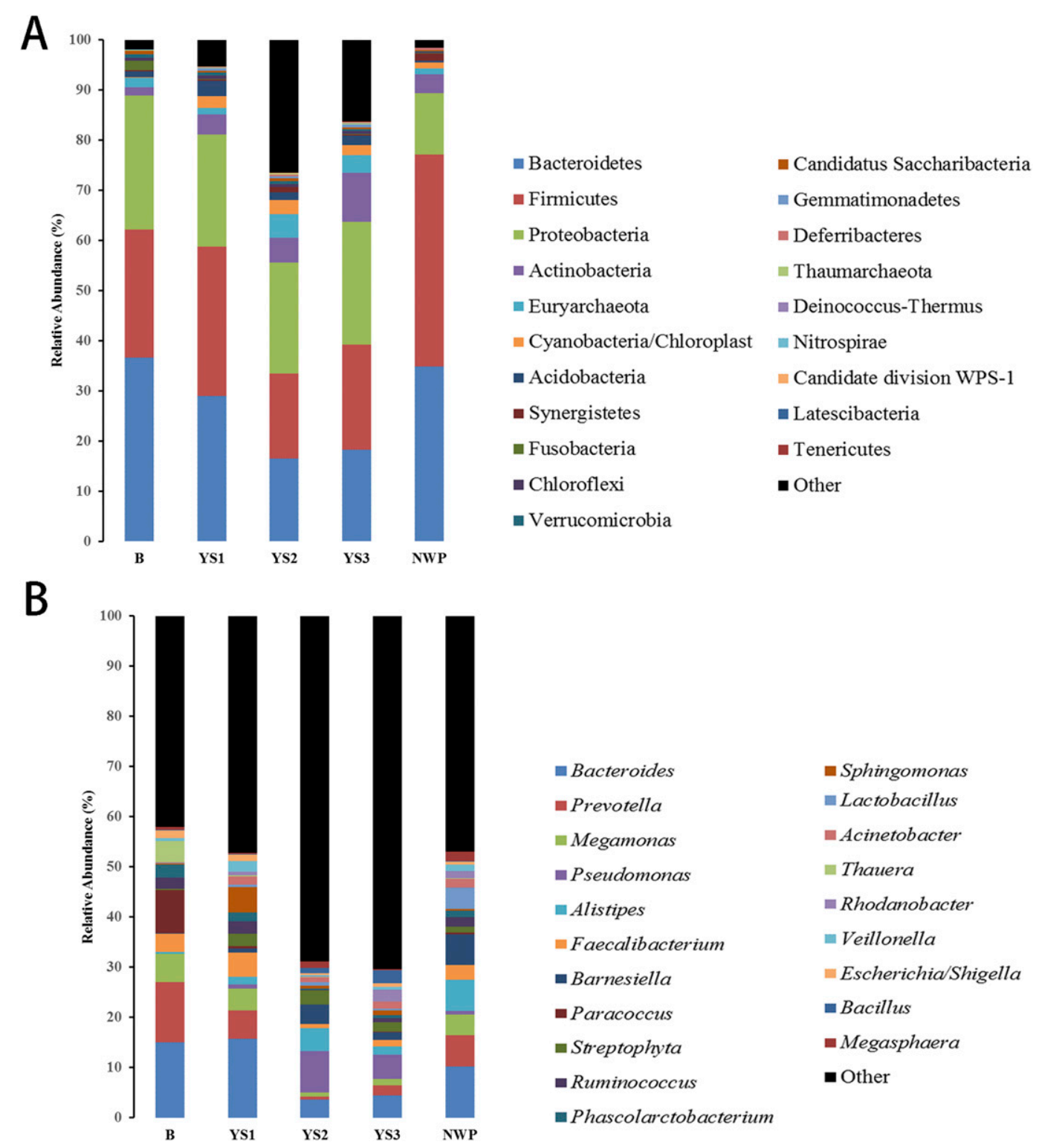

FIG. 4. Relative abundances of microbial groups in marine aerosols from different sites at the (a) phylum and (b) genus levels.

(temperature, relative humidity, wind speed, and wind direction) had no significant effects on bacterial community structure in both fine and coarse particles $(p>0.05)$. Wind direction had a greater impact on bacterial community structures in fine particles, and wind speed had the greatest impact on bacterial community structures in coarse particles.

\section{e. Backward trajectory analysis}

Analysis of the backward trajectories of the air masses showed that samples from the sites in the Bohai and Yellow Seas were collected mainly from continental air masses (Figs. 9a-d), and samples from the NWP site were collected from mixed continental and oceanic air masses (Fig. 9e).

\section{Summary and discussion}

Bacteria are important components of bioaerosols and are widely distributed in aerosols. Studies have found that the structures of bacterial communities in marine bioaerosols are complex and diverse (Seifried et al. 2015; Xia et al. 2015). However, studies on the community structures of bacteria in marine aerosols of different particle sizes have not been reported. We obtained 4448 OTUs from 26 aerosol samples of different 
A
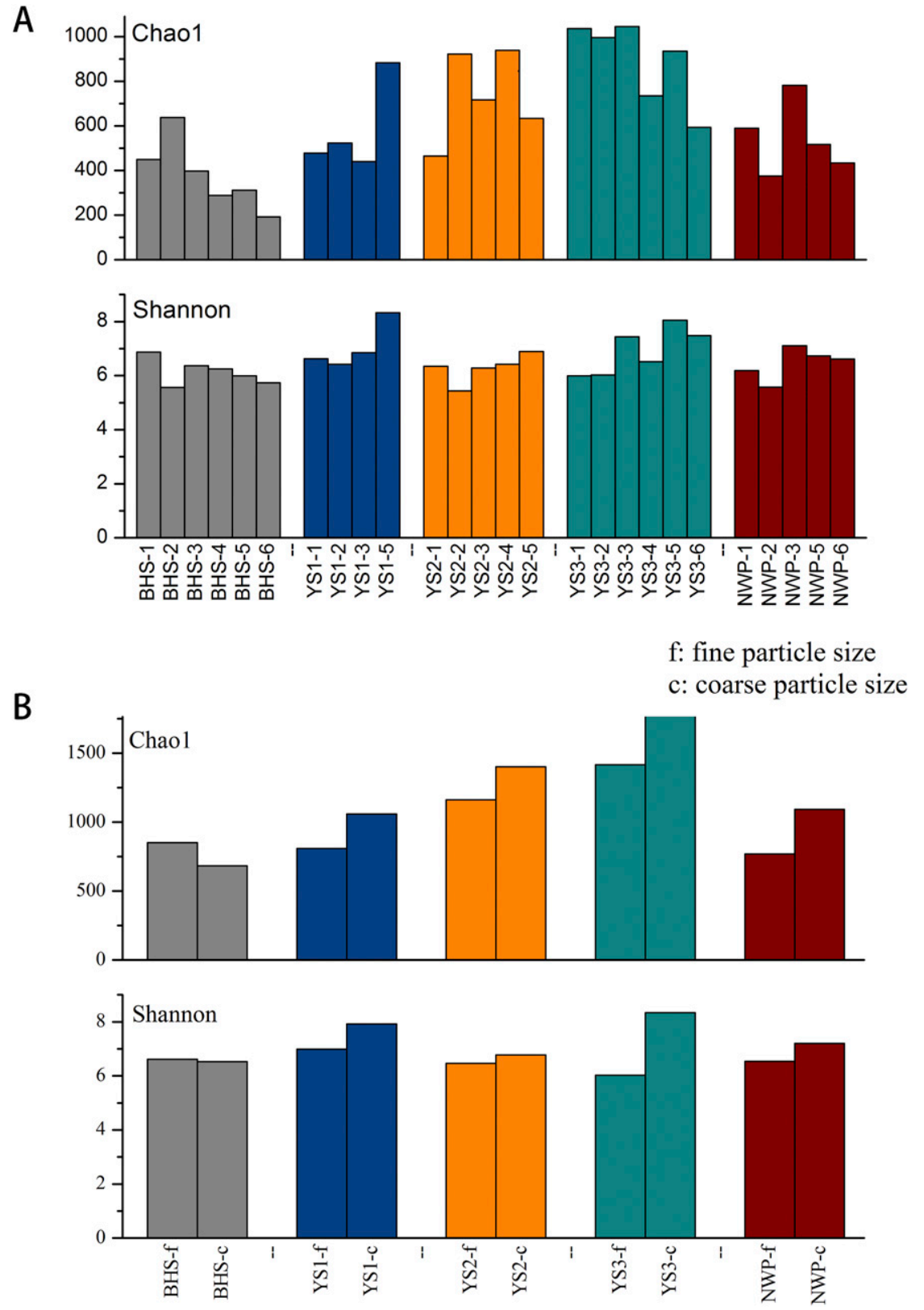

FIG. 5. Diversity of bacterial communities in marine aerosols (a) of different particle sizes and $(b)$ in the coarse $(>2.1 \mu \mathrm{m})$ and fine particle $(<2.1 \mu \mathrm{m})$ sizes.

particle sizes from five sites using Illumina highthroughput sequencing. Ma et al. (2017) found that the Chao1 and Shannon indices of bacterial communities in bioaerosols sampled in winter in the coastal region of Qingdao ranged from 78.6 to 287.4 and from 4.31 to 7.00 , respectively. The bacterial community structures in marine bioaerosols of different particle sizes were more complex and diverse than the bacterial communities in winter aerosols from Qingdao.
The bacterial community structures in the coarse particle were found to be more complex and diverse than those in fine particle in marine bioaerosols from the Yellow Sea and the northwestern Pacific Ocean, which was consistent with the results of a study on the community structures of bioaerosols from the Qingdao coastal region (Ma et al. 2017). It has been reported that microbes are mainly distributed in the coarse particle size (Dong et al. 2016; Li et al. 2011), and the bacterial richness in fine particulate matter $\left(\mathrm{PM}_{2.5}\right)$ has been 

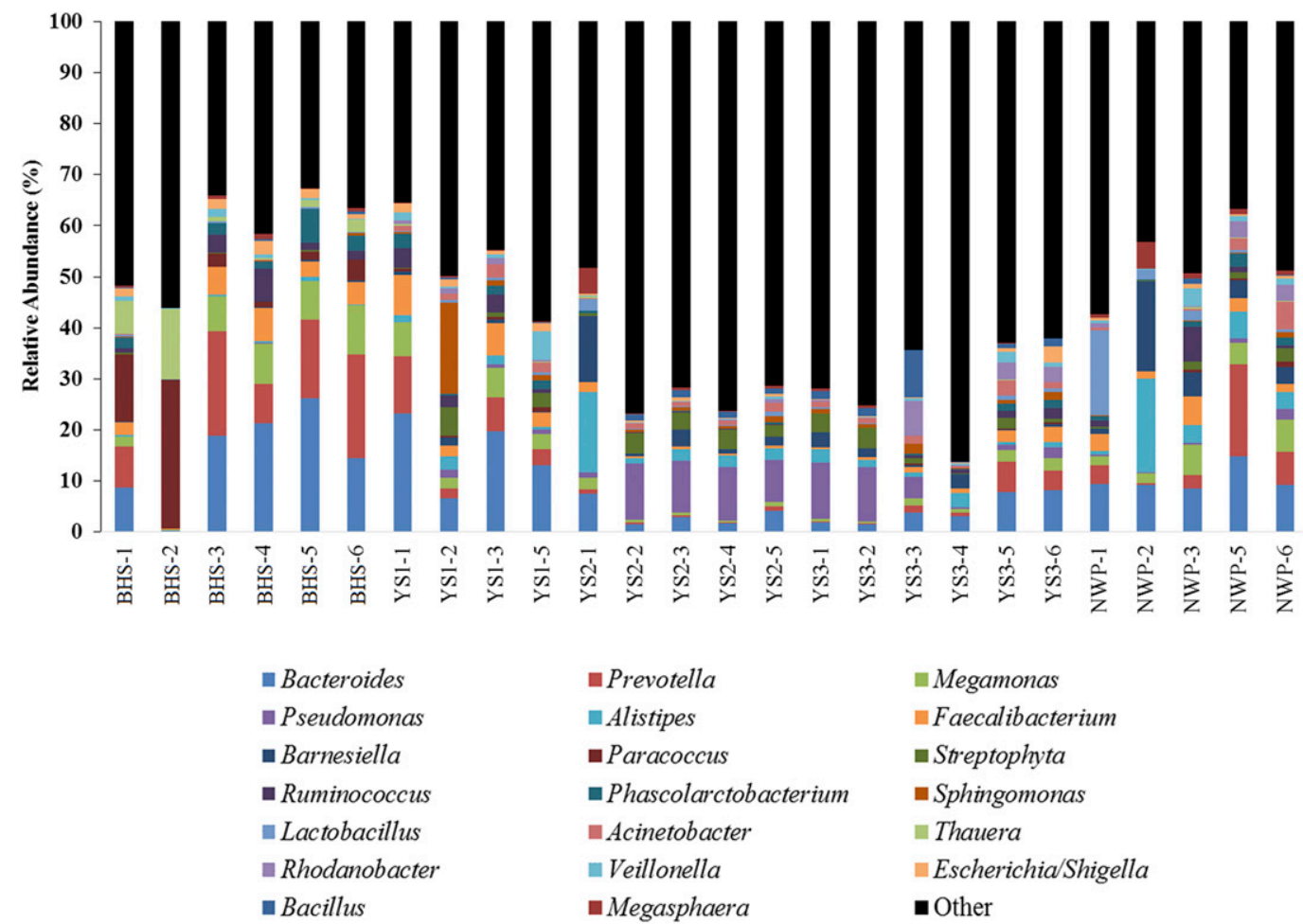

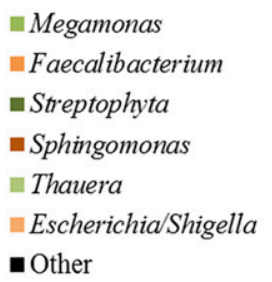

FIG. 6. Relative abundances of microbial groups in marine aerosols of different particle sizes at the genus level.

shown to be lower than that in coarse particulate matter $\left(\mathrm{PM}_{2.5-10}\right)$ (Bowers et al. 2013); however, the bacterial richness and diversity in the coarse particle was lower than that in the fine particle from the BHS site. The Bohai Sea is a semienclosed inland sea known to have a high population density and significant emissions of fine particulate matter and gaseous precursors (Van Donkelaar et al. 2010). Fine particles in Bohai Sea aerosols have been found to be mainly from continents, and aerosols over the Bohai Sea were relatively enriched in fine particles from anthropogenic sources compared with those over the Yellow Sea (Fu et al. 2015), which results in the bacterial community structure of the fine particle size in Bohai Sea aerosols being more complex and diverse. In the aerosols of fine particle size over the Bohai Sea, Paracoccus was an obvious dominant bacterial genus, which may mainly originated from the adjacent continent.

In our study, among the different sites, the 5.82\% shared OTUs accounted for $59.18 \%$ of all the bacterial sequences; the 19 shared phyla accounted for $89.50 \%$ of all the bacterial sequences; and the 130 shared genera accounted for $63.60 \%$ of all the bacterial sequences. The main groups of bacteria in the different sites were consistent, but the proportions of the different species varied; for example, Bacteroides was a dominant genus at

TABLE 3. Species shared by marine aerosol samples of all particle sizes.

\begin{tabular}{ccc}
\hline \hline Classification level & $\begin{array}{c}\text { Total number of species shared by } \\
\text { samples of all particle sizes }\end{array}$ & $\begin{array}{c}\text { Species shared by samples } \\
\text { of all particle sizes }\end{array}$ \\
\hline OTU & $13(20.30 \%$ of all the bacterial sequences $)$ & $\begin{array}{c}\text { OTU120, OTU2, OTU4, OTU6, OTU7, OTU50, OTU12, } \\
\text { OTU13, OTU10, OTU11, OTU16, OTU681, OTU30 } \\
\text { Phylum }\end{array}$ \\
Euryarchaeota, Acidobacteria, Actinobacteria, Bacteroidetes, \\
Firmicutes, Proteobacteria \\
Genus
\end{tabular}


A

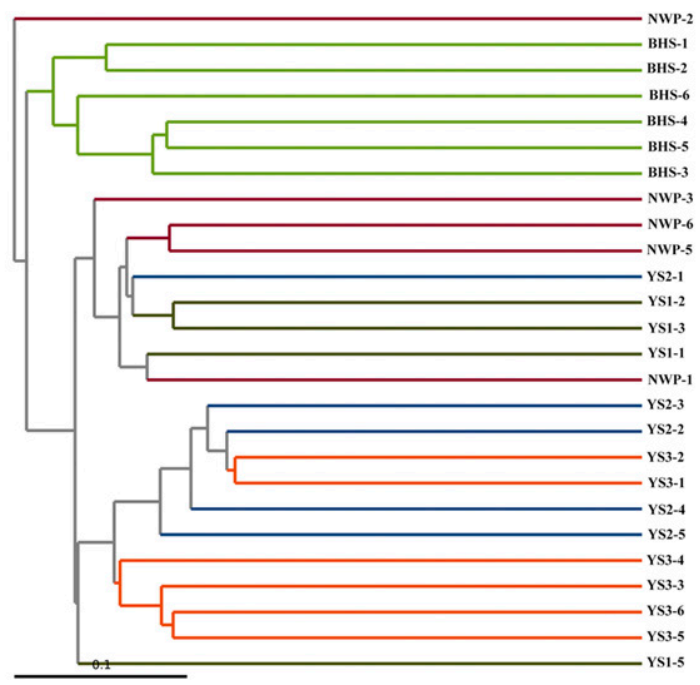

B

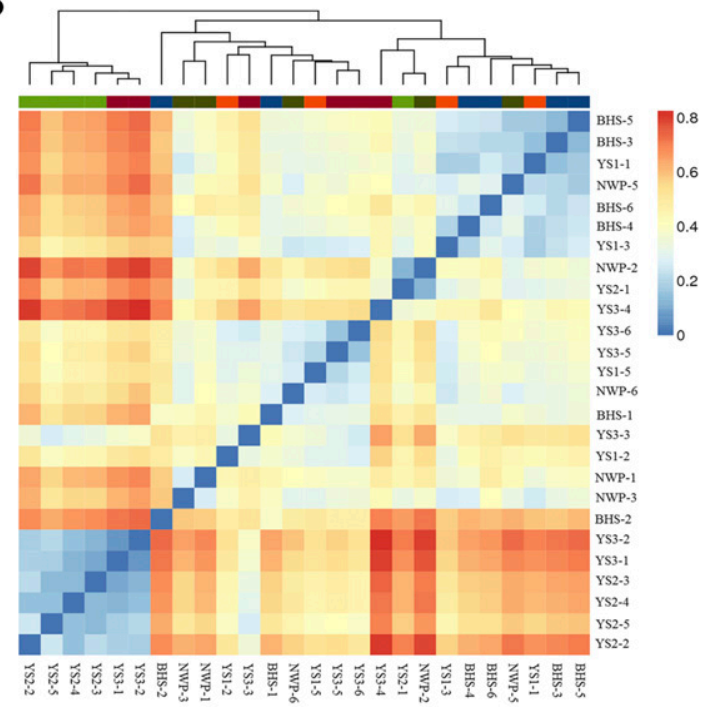

FIG. 7. (a) Cluster of each particle sample based on unweighted UniFrac distance metrics and (b) beta diversity heat map of bacterial community composition in marine aerosols based on weighted UniFrac distance metrics.

all sites. Studies have indicated that there may be a bacterial background in the atmosphere in the form of several dominant taxa (Gandolfi et al. 2013). Seifried et al. (2015) found that 37 OTUs in marine aerosols constituted more than $75 \%$ of all of the sequences, and the dominant OTU in all of the samples, accounting for $17 \%$ of all the bacterial sequences, was assigned to the genus Sphingomonas, which is known to be ubiquitous in the environment (Fahlgren et al. 2010; Harrison et al. 2005; Li et al. 2010; Zweifel et al. 2012). Our study also supports the hypothesis that there may be a bacterial background in the atmosphere in the form of several dominant taxa. However, among the aerosols of different particle sizes at all of the sites, 13 shared OTUs accounted for $20.30 \%$ of all the bacterial sequences, 6 shared phyla accounted for $84.60 \%$ of all the bacterial sequences, and 18 shared genera accounted for $38.11 \%$ of all the bacterial sequences. Seifried et al. (2015) pointed out that there may be steady "bacterial core communities" in the atmosphere, possibly from strong regional sources, such as tropical rain forests, big grass fields, or soil areas, which are constantly distributed and mixed over long distances. Some bacteria, which were the dominant species in the present study, such as Bacteroides, Prevotella, Pseudomonas, and Bacillus, were also dominant bacteria in other bioaerosol studies that investigated marine/coastal ecosystems (Seifried et al. 2015; Cho and Hwang 2011; Xia et al. 2015; Ma et al. 2017). In addition, Megamonas, which is mainly isolated from human or animal intestines, was a dominant bacterial genus in the present study. The relative abundances of these bacteria of different particle sizes varied.
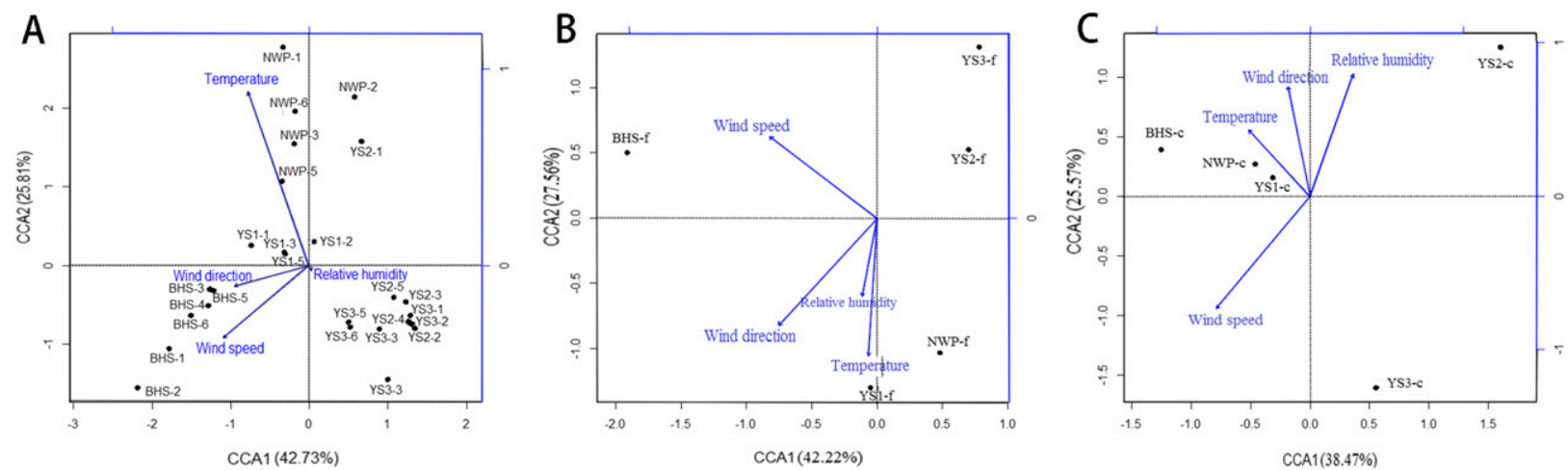

FIG. 8. CCA showing the relationships between environmental factors and the community structures of marine airborne bacteria in (a) aerosols of each particle size, (b) fine particles, and (c) coarse particles. 
A NOAA HYSPLIT MODEL
Backward trajectory ending at 1500 UTC 13 May 14 GDAS Meteorological Data

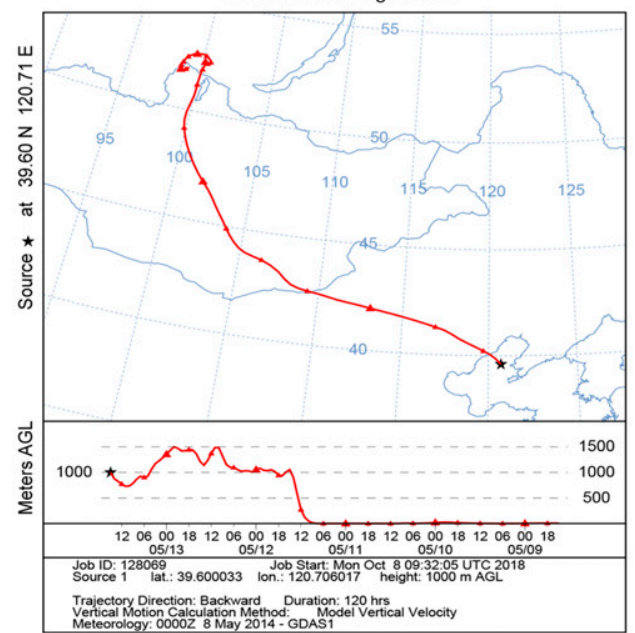

$\mathrm{C}$ Backward trajectory ending at 1000 UTC 30 Apr 14 GDAS Meteorological Data

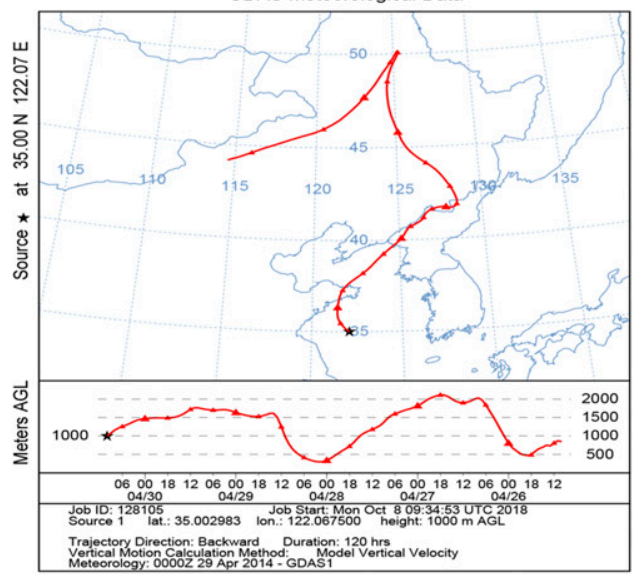

E

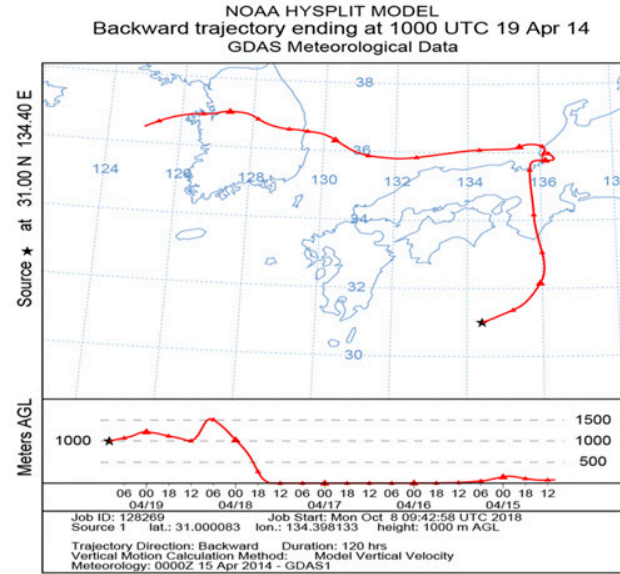

B NOAA HYSPLIT MODEL Backward trajectory ending at 0800 UTC 17 May 14 GDAS Meteorological Data

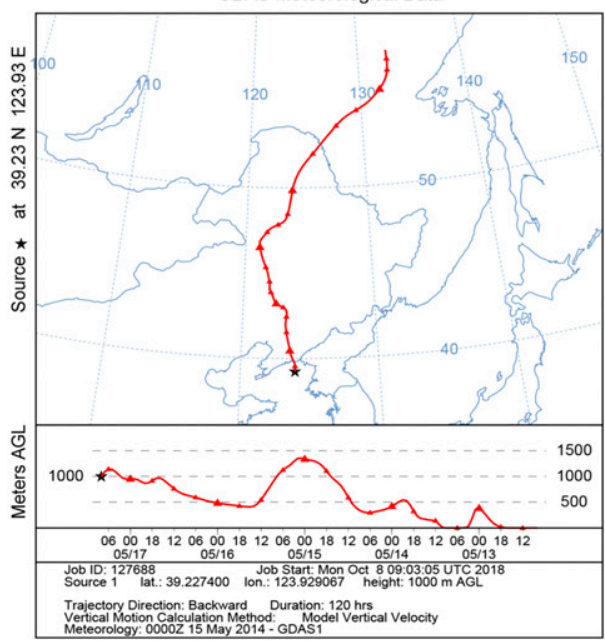

D Backward trajeAA HYSPLIT MODEL UTC 18 Mar 14

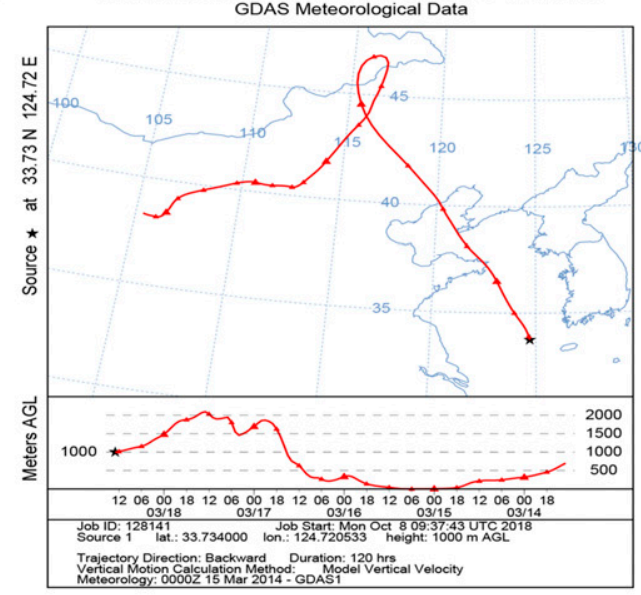

FIG. 9. Backward trajectory analysis of air masses at the start positions for sampling areas: (a) BHS, (b) YS1, (c) YS2, (d) YS3, and (e) NWP. 
Our study further indicated that there may be a bacterial background in the atmosphere in the form of several dominant taxa and that bacteria in aerosols are mixed constantly during transmission, which contributes to the redistribution of bacteria among the aerosols of different particle sizes.

The dominant phyla in the aerosols at different sites were consistent, but the dominant genera were different. The dominant phyla were Bacteroidetes, Firmicutes, and Proteobacteria. These three phyla have been reported to be dominant in marine aerosols, but the dominant phyla over different sea areas were different (Seifried et al. 2015; Cho and Hwang 2011; Xia et al. 2015). The dominant genera in bioaerosols from different sites were different. Xia et al. (2015) also found that the general bacterial communities in the aerosol over different sea areas were markedly different. Bacteroides was a dominant genus at all sites, but its relative abundances at the different sites were different. Bacteroides species were detected in a variety of environments (Elmir et al. 2009; Green et al. 2011; Ma et al. 2017; Sattar 2014). The bacterial compositions of the coarse and fine particles from the same site also varied. The dominant genera of the coarse particle sizes at the same site were generally more similar, but the dominant genera of fine particle sizes were quite different except for the YS3 site. Fine particles (diameter $<2 \mu \mathrm{m}$ ) have a long residence time in the atmosphere (days to weeks) and can be transported over long distances (Dueker et al. 2011). Long-distance transport of terrestrial aerosols may affect the composition and size distribution of bacterial communities in marine aerosols.

Studies have shown that the differences in bacterial community composition among the sampling locations were affected by the sampling locality itself and their adjacent ecosystems (Seifried et al. 2015). The bacterial taxa in the aerosols were obviously affected by geographical location, which may be the joint role of the sampling location itself and the adjacent ecological ecosystems. The relative abundances of these taxa of different particle sizes varied, leading to the differences in community structures of different particle sizes at different sites. Cho and Hwang (2011) inferred that the occurrences of different major OTUs in air over space and time could not be due to successful adaptations of rare phylotypes to air, but rather to the variation of their sources and emissions affected by local meteorological conditions, as the inference of significant bacterial growth in air is unlikely (Burrows et al. 2009a). The differences in community structures of different particle sizes would be due to the continuous mixing of bacteria in the transmission process and variations in bacteria in the sources; their emission into the air would be affected by the local meteorological conditions.

Among the observed meteorological factors, temperature had the greatest impact on bacterial community structure. Temperature significantly influenced $(p=$ 0.001 ) the bacterial communities of marine aerosols of different particle sizes. It has been reported that bacterial communities in both terrestrial and marine aerosols can be clearly affected by temperature (Gandolfi et al. 2013; Seifried et al. 2015; Zhen et al. 2017). Samples were collected in the spring of 2014, with atmospheric temperatures ranging from $11.9^{\circ}$ to $19.8^{\circ} \mathrm{C}$. An increase in temperature can increase aerosol bacterial input and accelerate the movement of convective air, thereby increasing the dispersion of bacteria in the atmosphere (Zhen et al. 2017). In addition, temperature can affect the particle size distribution of aerosols (Lin 2009), thus affecting the particle size distribution of the bacteria in aerosols.

Wind speed had the greatest impact on bacterial community structure in coarse particles (though not significant) and a significant influence $(p=0.019)$ on bacterial communities in marine aerosols of the different particle sizes. Zhen et al. (2017) found that under conditions of high wind strength in the spring, bacterial communities can be affected by dust from various surfaces. Hu et al. (2017) discovered that strong winds over sea surfaces can increase the contribution of oceanic emissions to the concentrations of viable bacteria in aerosols, and the concentration of bacteria is significantly higher when the wind speed is greater than $5.4 \mathrm{~m} \mathrm{~s}^{-1}$ (exceeding a Beaufort force of 3 , at which wave breaking can occur). The wind speeds at the BHS, YS3 and NWP sites were all greater than $5.4 \mathrm{~m} \mathrm{~s}^{-1}$, which could increase the contribution of surface seawater sources, especially for coarse particles (Wu 1992; Veron 2015), thereby increasing the differences in bacterial community composition between the coarse and fine particles.

In our study, bacteria associated with $\mathrm{CCN}$ and IN were detected, and the more abundant genera were Pseudomonas, Sphingomonas, and Bacillus. Sphingomonas, Pseudomonas, and Bacillus are CCN bacteria and IN bacteria (Maki et al. 1974; Šantl-Temkiv et al. 2015; Hirano and Upper 2000). Pseudomonas strains can use surfactants to facilitate their activation from aerosols into CCN (Ahern et al. 2007). Bacillus strains can also produce surfactants and have certain effects on the formation of CCN (Maki et al. 1974; Šantl-Temkiv et al. 2015; Hirano and Upper 2000). Particles can be transported from Earth's surface to the troposphere by convective transport (Burrows et al. 2009b). Studies have found high proportions of bacteria that typically live on 
plant surfaces in cumulonimbus clouds, a particular type of a convective cloud (Šantl-Temkiv et al. 2012, 2013). Microorganisms of small particle sizes have a long residence time in the atmosphere and can be transferred to the upper troposphere to reflect or absorb incident light, which affects the formation of clouds and changes the chemical reactions in clouds (Yin et al. 2012; Franzetti et al. 2011). Pseudomonas, Sphingomonas, and Bacillus all exist in fine particles, with possible effects on $\mathrm{CCN}$ and INP. Further studies are needed to understand the effects of marine aerosol microorganisms on CCN and INP.

\section{Conclusions}

This study indicates that bacterial community structures in marine bioaerosols of different particle sizes are complex and diverse. The bacterial taxa in these aerosols were obviously affected by geographical location. The dominant species were different over different sea areas. The bacterial compositions of the coarse and fine particles from the same location also varied. The compositions of these communities can be affected by the differences in both sampling site and particle size. Among the environmental factors examined, temperature- and wind-speedinfluenced bacterial communities in marine aerosols of different particle sizes. Our results further confirmed that the bacteria in aerosols have a background that is formed by several species and that the bacteria in aerosols are mixed constantly during transmission. In our next study, we will determine the chemical composition and continue to delve into the problems of aerosol microbial transmission and mixing.

Acknowledgments. This work was supported by the National Natural Science Foundation of China (Grant 41775148) and the Fundamental Research Funds for the Central Universities (Grant 201762006). Thank you to Zhong Xi and Dong Lijie for their help in the sampling process and the guidance given by Shao Congcong in the experiment. We thank Professor Qi Jianhua for her guidance in the process of revising the article. All of the authors declare that there are no conflicts of interest. The authors would also like to thank the editor and anonymous reviewers for their valuable comments and suggestions to improve the quality of this paper.

\section{REFERENCES}

Ahern, H. E., K. A. Walsh, T. C. J. Hill, and B. F. Moffett, 2007: Fluorescent pseudomonads isolated from Hebridean cloud and rain water produce biosurfactants but do not cause ice nucleation. Biogeosciences, 4, 115-124, https://doi.org/10.5194/bg-4-115-2007.

Aller, J. Y., M. R. Kuznetsova, C. J. Jahns, and P. F. Kemp, 2005: The sea surface microlayer as a source of viral and bacterial enrichment in marine aerosols. J. Aerosol Sci., 36, 801-812, https://doi.org/10.1016/j.jaerosci.2004.10.012.

Ariya, P. A., and M. Amyot, 2004: New directions: The role of bioaerosols in atmospheric chemistry and physics. Atmos. Environ., 38, 1231-1232, https://doi.org/10.1016/j.atmosenv.2003.12.006.

Bauer, H., H. Giebl, R. Hitzenberger, A. Kasper-Giebl, G. Reischl, F. Zibuschka, and H. Puxbaum, 2003: Airborne bacteria as cloud condensation nuclei. J. Geophys. Res., 108, 4658, https:// doi.org/10.1029/2003JD003545.

Bowers, R. M., N. Clements, J. B. Emerson, C. Wiedinmyer, M. P. Hannigan, and N. Fierer, 2013: Seasonal variability in bacterial and fungal diversity of the near-surface atmosphere. Environ. Sci. Technol., 47, 12 097-12 106, https://doi.org/10.1021/ es402970s.

Burrows, S. M., W. Elbert, M. G. Lawrence, and U. Poschl, 2009a: Bacteria in the global atmosphere-Part 1: Review and synthesis of literature data for different ecosystems. Atmos. Chem. Phys., 9, 9263-9280, https://doi.org/10.5194/acp-9-9263-2009.

—, T. Butler, P. Jöckel, H. Tost, A. Kerkweg, U. Pöschl, and M. G. Lawrence, 2009b: Bacteria in the global atmospherePart 2: Modeling of emissions and transport between different ecosystems. Atmos. Chem. Phys., 9, 9281-9297, https://doi.org/ 10.5194/acp-9-9281-2009.

Caporaso, J. G., and Coauthors, 2010: QIIME allows analysis of high-throughput community sequencing data. Nat. Methods, 7 , 335-336, https://doi.org/10.1038/nmeth.f.303.

Cho, B. C., and C. Y. Hwang, 2011: Prokaryotic abundance and 16S rRNA gene sequences detected in marine aerosols on the East Sea (Korea). FEMS Microbiol. Ecol., 76, 327-341, https://doi.org/ 10.1111/j.1574-6941.2011.01053.x.

Christner, B. C., 2010: Bioprospecting for microbial products that affect ice crystal formation and growth. Appl. Microbiol. Biotechnol., 85, 481-489, https://doi.org/10.1007/s00253-009-2291-2.

Cole, J. R., and J. M. Tiedje, 2014: History and impact of RDP: A legacy from Carl Woese to microbiology. RNA Biol., 11, 239243, https://doi.org/10.4161/rna.28306.

Delang, C. O., and W. M. Li, 2013: Species richness and diversity. Ecological Succession on Fallowed Shifting Cultivation Fields, Springer, 39-66.

Deleon-Rodriguez, N., and Coauthors, 2013: Microbiome of the upper troposphere: Species composition and prevalence, effects of tropical storms, and atmospheric implications. Proc. Natl. Acad. Sci. USA, 110, 2575-2580, https://doi.org/10.1073/pnas.1212089110.

Diehl, K., C. Quick, S. Matthias-Maser, S. K. Mitra, and R. Jaenicke, 2001: The ice nucleating ability of pollen: Part I: Laboratory studies in deposition and condensation freezing modes. Atmos. Res., 58, 75-87, https://doi.org/10.1016/S01698095(01)00091-6.

Dong, L., and Coauthors, 2016: Concentration and size distribution of total airborne microbes in hazy and foggy weather. Sci. Total Environ., 541, 1011-1018, https://doi.org/10.1016/ j.scitotenv.2015.10.001.

Draxler, R., and G. Rolph, 2013: HYSPLIT (Hybrid Single-Particle Lagrangian Integrated Trajectory). NOAA Air Resources Laboratory, https://ready.arl.noaa.gov/HYSPLIT.php.

Dueker, M. E., K. C. Weathers, G. D. O’Mullan, A. R. Juhl, and M. Uriarte, 2011: Environmental controls on coastal coarse aerosols: Implications for microbial content and deposition in the near-shore environment. Environ. Sci. Technol., 45, 33863392, https://doi.org/10.1021/es1035128.

Dusek, U., and Coauthors, 2006: Size matters more than chemistry for cloud-nucleating ability of aerosol particles. Science, $\mathbf{3 1 2}$, 1375-1378, https://doi.org/10.1126/science.1125261. 
Edgar, R. C., 2013: UPARSE: Highly accurate OTU sequences from microbial amplicon reads. Nat. Methods, 10, 996-998, https://doi.org/10.1038/nmeth.2604.

Elmir, S. M., and Coauthors, 2009: Quantitative evaluation of enterococci and Bacteroidales released by adults and toddlers in marine water. Water Res., 43, 4610-4616, https://doi.org/ 10.1016/j.watres.2009.07.006.

Fahlgren, C., Å. Hagström, D. Nilsson, and U. L. Zweifel, 2010: Annual variations in the diversity, viability, and origin of airborne bacteria. Appl. Environ. Microbiol., 76, 3015-3025, https://doi.org/10.1128/AEM.02092-09.

Franc, G. D., and P. J. Demott, 1998: Cloud activation characteristics of airborne Erwinia carotovora cells. J. Appl. Meteor., 37, 1293-1300, https://doi.org/10.1175/1520-0450(1998)037<1293: CACOAE $>2.0 . \mathrm{CO} ; 2$.

Franzetti, A., I. Gandolfi, E. Gaspari, R. Ambrosini, and G. Bestetti, 2011: Seasonal variability of bacteria in fine and coarse urban air particulate matter. Appl. Microbiol. Biotechnol., 90, 745-753, https://doi.org/10.1007/s00253-010-3048-7.

Fröhlich-Nowoisky, J., and Coauthors, 2016: Bioaerosols in the earth system: Climate, health, and ecosystem interactions. Atmos. Res., 182, 346-376, https://doi.org/10.1016/j.atmosres.2016.07.018.

Fu, H., M. Zheng, C. Yan, X. Li, H. Gao, X. Yao, Z. Guo, and Y. Zhang, 2015: Sources and characteristics of fine particles over the Yellow Sea and Bohai Sea using online single particle aerosol mass spectrometer. J. Environ. Sci., 29, 62-70, https:// doi.org/10.1016/j.jes.2014.09.031.

Gandolfi, I., V. Bertolini, R. Ambrosini, G. Bestetti, and A. Franzetti, 2013: Unravelling the bacterial diversity in the atmosphere. Appl. Microbiol. Biotechnol., 97, 4727-4736, https://doi.org/10.1007/s00253-013-4901-2.

Garcia, E., T. C. J. Hill, A. J. Prenni, P. J. Demott, G. D. Franc, and S. M. Kreidenweis, 2012: Biogenic ice nuclei in boundary layer air over two U.S. High Plains agricultural regions. J. Geophys. Res., 117, D18209, https://doi.org/10.1029/ 2012JD018343.

Green, H. C., O. C. Shanks, M. Sivaganesan, R. A. Haugland, and K. G. Field, 2011: Differential decay of human faecal Bacteroides in marine and freshwater. Environ. Microbiol., 13, 32353249, https://doi.org/10.1111/j.1462-2920.2011.02549.x.

Grinshpun, S. A., and J. M. Clark, 2005: Measurement and characterization of bioaerosols. J. Aerosol Sci., 36, 553-555, https:// doi.org/10.1016/j.jaerosci.2005.03.001.

Harrison, R. M., and Coauthors, 2005: Climate factors influencing bacterial count in background air samples. Int. J. Biometeorol., 49, 167-178, https://doi.org/10.1007/s00484-004-0225-3.

Hirano, S. S., and C. D. Upper, 2000: Bacteria in the leaf ecosystem with emphasis on Pseudomonas syringae-A pathogen, ice nucleus, and epiphyte. Microbiol. Mol. Biol. Rev., 64, 624-653, https://doi.org/10.1128/MMBR.64.3.624-653.2000.

Ho, J., and S. Duncan, 2005: Estimating aerosol hazards from an anthrax letter. J. Aerosol Sci., 36, 701-719, https://doi.org/ 10.1016/j.jaerosci.2004.11.019.

Hu, W., K. Murata, S. Fukuyama, Y. Kawai, E. Oka, M. Uematsu, and D. Zhang, 2017: Concentration and viability of airborne bacteria over the Kuroshio Extension region in the northwestern Pacific Ocean: Data from three cruises. J. Geophys. Res. Atmos., 122, 12 892-12 905, https://doi.org/10.1002/ 2017JD027287.

Kalogerakis, N., D. Paschali, V. Lekaditis, A. Pantidou, K. Eleftheriadis, and M. Lazaridis, 2005: Indoor air quality-Bioaerosol measurements in domestic and office premises. J. Aerosol Sci., 36, 751-761, https://doi.org/10.1016/j.jaerosci.2005.02.004.
Li, K., S. Dong, Y. Wu, and M. Yao, 2010: Comparison of the biological content of air samples collected at ground level and at higher elevation. Aerobiologia, 26, 233-244, https://doi.org/ 10.1007/s10453-010-9159-x.

Li, M., J. Qi, H. Zhang, S. Huang, L. Li, and D. Gao, 2011: Concentration and size distribution of bioaerosols in an outdoor environment in the Qingdao coastal region. Sci. Total Environ., 409, 3812-3819, https://doi.org/10.1016/j.scitotenv.2011.06.001.

Lin, J., 2009: Relationship between meteorological conditions and particle size distribution of atmospheric aerosols (in Chinese). J. Meteor. Environ., 25, 1-5.

Ma, M., Y. Zhen, M. I. Tie-Zhu, Q. I. Jian-Hua, C. C. Shao, and W. R. Feng, 2017: Bacterial community characteristics in different particle sizes of bioaerosols in winter haze days in Qingdao (in Chinese). Zhongguo Huanjing Kexue, 37, 2855-2865.

Maki, L. R., E. L. Galyan, M. M. Changchien, and D. R. Caldwell, 1974: Ice nucleation induced by Pseudomonas syringae. Appl. Microbiol., 28, 456-459.

Maki, T., Y. Kurosaki, K. Onishi, K. C. Lee, S. B. Pointing, D. Jugder, N. Yamanaka, H. Hasegawa, and M. Shinoda, 2017: Variations in the structure of airborne bacterial communities in Tsogt-Ovoo of Gobi desert area during dust events. Air Qual. Atmos. Health, 10, 249-260, https://doi.org/10.1007/s11869-016-0430-3.

Masella, A. P., A. K. Bartram, J. M. Truszkowski, D. G. Brown, and J. D. Neufeld, 2012: PANDAseq: Paired-end assembler for illumina sequences. BMC Bioinf., 13, 31-37, https://doi.org/ 10.1186/1471-2105-13-31.

Morris, C. E., D. G. Georgakopoulos, and D. C. Sands, 2004: Ice nucleation active bacteria and their potential role in precipitation. J. Phys. IV , 121, 87-103, https://doi.org/10.1051/jp4: 2004121004.

Polymenakou, P. N., M. Mandalakis, E. G. Stephanou, and A. Tselepides, 2008: Particle size distribution of airborne microorganisms and pathogens during an intense African dust event in the eastern Mediterranean. Environ. Health Perspect., 116, 292-296, https://doi.org/10.1289/ehp.10684.

Qi, J. H., Q. Shao, W. Xu, D. Gao, and C. Jin, 2014: Seasonal distribution of bioaerosols in the coastal region of Qingdao. J. Ocean Univ. China, 13, 57-65, https://doi.org/10.1007/ s11802-014-1951-8.

_ - X. Zhong, Q. Shao, D. Gao, L. Wu, L. Huang, and Y. Ye, 2015: Microbial activity levels in atmospheric bioaerosols in Qingdao. Aerobiologia, 31, 353-365, https://doi.org/10.1007/ s10453-015-9369-3.

Roggenbuck, M., and Coauthors, 2014: The microbiome of New World vultures. Nat. Commun., 5, 5498-5504, https://doi.org/ 10.1038/ncomms6498.

Sanjit, L., and D. Bhatt, 2005: How relevant are the concepts of species diversity and species richness? J. Biosci., 30, 557-560, https://doi.org/10.1007/BF02703552.

Šantl-Temkiv, T., K. Finster, B. M. Hansen, N. W. Nielsen, and U. G. Karlson, 2012: The microbial diversity of a storm cloud as assessed by hailstones. FEMS Microbiol. Ecol., 81, 684-695, https://doi.org/10.1111/j.1574-6941.2012.01402.x.

—, , T. Dittmar, B. M. Hansen, R. Thyrhaug, N. W. Nielsen, and U. G. Karlson, 2013: Hailstones: A window into the microbial and chemical inventory of a storm cloud. PLoS One, 8, e53550, https://doi.org/10.1371/journal.pone.0053550.

— active bacteria and bacterial fragments. Atmos. Environ., 109, 105-117, https://doi.org/10.1016/j.atmosenv.2015.02.060.

Sattar, A. A., 2014: Lipopolysaccharide in marine bathing water; a potential real-time biomarker of bacterial contamination 
and relevance to human health. Thesis, School of Biomedical and Healthcare Sciences, Plymouth University Peninsula Schools of Medicine and Dentistry, 246 pp., https://pearl.plymouth.ac.uk/bitstream/handle/10026.1/ 3185/2014\%20Sattar\%2010250431\%20PhD.pdf;sequence=1.

Seifried, J. S., A. Wichels, and G. Gerdts, 2015: Spatial distribution of marine airborne bacterial communities. MicrobiologyOpen, 4, 475-490, https://doi.org/10.1002/mbo3.253.

Singh, H. B., and Coauthors, 2001: Global distribution and sources of volatile and nonvolatile aerosol in the remote troposphere. J. Geophys. Res., 107, 4121, https://doi.org/ 10.1029/2001JD000486.

Vali, G., P. J. DeMott, O. Möhler, and T. F. Whale, 2015: A proposal for ice nucleation terminology. Atmos. Chem. Phys., 15, 10 263-10270, https://doi.org/10.5194/acp-15-10263-2015.

Van Donkelaar, A., R. V. Martin, M. Brauer, R. Kahn, R. Levy, C. Verduzco, and P. J. Villeneuve, 2010: Global estimates of ambient fine particulate matter concentrations from satellitebased aerosol optical depth: Development and application. Environ. Health Perspect., 118, 847-855, https://doi.org/ 10.1289/ehp.0901623.

Van Leuken, J. P. G., A. N. Swart, P. Droogers, A. V. Pul, D. Heederik, and A. H. Havelaar, 2016: Climate change effects on airborne pathogenic bioaerosol concentrations: a scenario analysis. Aerobiologia, 32, 607-617, https://doi.org/ 10.1007/s10453-016-9435-5.

Veron, F., 2015: Ocean spray. Annu. Rev. Fluid Mech., 47, 507-538, https://doi.org/10.1146/annurev-fluid-010814-014651.

Wu, J., 1992: Bubble flux and marine aerosol spectra under various wind velocities. J. Geophys. Res. Oceans, 97, 2327-2333, https://doi.org/10.1029/91JC02568.

Wu, L., 2014: Microbial community diversity of bioaerosols in Qingdao and the Yellow Sea (in Chinese). Thesis,
Department of Environmental Science, Ocean University of China, $71 \mathrm{pp}$.

Xia, X., J. Wang, J. Ji, J. Zhang, L. Chen, and R. Zhang, 2015: Bacterial communities in marine aerosols revealed by 454 pyrosequencing of the 16S rRNA gene. J. Atmos. Sci., 72, 2997-3008, https://doi.org/10.1175/JAS-D-15-0008.1.

$\mathrm{Xu}, \mathrm{C}$, and Coauthors, 2017: Bacterial characterization in ambient submicron particles during severe haze episodes at Ji'nan, China. Sci. Total Environ., 580, 188-196, https://doi.org/ 10.1016/j.scitotenv.2016.11.145.

Yin, Y., Q. Chen, L. Jin, B. Chen, S. Zhu, and X. Zhang, 2012: The effects of deep convection on the concentration and size distribution of aerosol particles within the upper troposphere: A case study. J. Geophys. Res., 117, D22202, https://doi.org/ 10.1029/2012JD017827.

Zhen, Q., Y. Deng, Y. Wang, X. Wang, H. Zhang, X. Sun, and Z. Ouyang, 2017: Meteorological factors had more impact on airborne bacterial communities than air pollutants. Sci. Total Environ., 601-602, 703-712, https://doi.org/10.1016/ j.scitotenv.2017.05.049.

Zhong, X., J. Qi, H. Li, L. Dong, and D. Gao, 2016: Seasonal distribution of microbial activity in bioaerosols in the outdoor environment of the Qingdao coastal region. Atmos. Environ., 140, 506-513, https://doi.org/10.1016/j.atmosenv.2016.06.034.

Zhu, C., K. Kawamura, and B. Kunwar, 2015: Organic tracers of primary biological aerosol particles at subtropical Okinawa Island in the western North Pacific Rim. J. Geophys. Res. Atmos., 120, 5504-5523, https://doi.org/10.1002/2015JD023611.

Zweifel, U. L., Å. Hagström, K. Holmfeldt, R. Thyrhaug, C. Geels, L. M. Frohn, C. A. Skjøth, and U. G. Karlson, 2012: High bacterial 16S rRNA gene diversity above the atmospheric boundary layer. Aerobiologia, 28, 481-498, https://doi.org/ 10.1007/s10453-012-9250-6. 